Camila Ferraz Lucena Monaco

\title{
TRATAMENTO COM EPA E DHA PROTEGE CÉLULAS BETA PANCREÁTICAS CONTRA A DISFUNÇÃO INDUZIDA POR ÁCIDO PALMÍTICO
}

Tese apresentada ao Programa de Pós-Graduação em Fisiologia Humana do Instituto de Ciências Biomédicas da Universidade de São Paulo, para obtenção do título de Doutor em Ciências

Área de Concentração:

Fisiologia Humana

Orientador: Prof. Dr. Angelo Rafael Carpinelli

Versão original 


\section{RESUMO}

MONACO, C. F. L. Tratamento com EPA e DHA protege células beta pancreáticas contra a disfunção induzida por ácido palmítico. 2017. $84 \mathrm{p}$. Tese (Doutorado em Fisiologia Humana) - Instituto de Ciências Biomédicas, Universidade de São Paulo, São Paulo, 2017.

A secreção de insulina é estimulada pela glicose, porém os ácidos graxos (AG) podem influenciar o processo secretório induzido pela glicose. Os AG $\omega 3$ interferem em diversos processos fisiológicos, sendo que nas ilhotas pancreáticas, os AG $\omega 3$ colaboram para a diminuição da lipotoxicidade induzida pelo ácido palmítico.

Ao ácido palmítico são atribuídos efeitos deletérios em diversos tecidos, assim como nas células $\beta$, onde ele promove a alteração da composição dos fosfolípides de membrana, do potencial elétrico da mesma e consequentemente do processo de extrusão dos grânulos de insulina. A exposição crônica das células $\beta$ ao ácido palmítico é tóxica, provocando diminuição da resposta secretória de insulina, redução da oxidação e captação de glicose, culminando para a morte das células $\beta$. Além disso o ácido palmítico induz o aumento de espécies reativas de oxigênio (EROs) que em quantidades suprafisiológicas, irão contribuir também para a falência e morte da célula $\beta$.

As EROs podem ser de origem mitocondrial, através do metabolismo dos nutrientes ou ainda proveniente da ativação do complexo enzimático NADPH oxidase, o qual é modulado pela glicose e pelos AG, incluindo o ácido palmítico.

Em contrapartida, os AG $\omega 3$ exercem efeitos anti-inflamatórios e antioxidantes em diversos sistemas, contribuindo para melhora de perfil lipídico e resistência periférica à insulina. Nas células $\beta$, a partir dos resultados obtidos, a presença de AG $\omega 3$ mostrou-se eficaz para prevenir o dano secretório e o aumento de EROs, além de contribuir para manutenção da viabilidade celular e da captação de glicose nas ilhotas tratadas com ácido palmítico, desempenhando um importante papel protetor na célula $\beta$.

Palavras-chave: Ilhota Pancreática. Ácido Graxo Omega-3. Ácido Palmítico. Secreção de Insulina. EROs. NADPH oxidase. Apoptose. 


\begin{abstract}
MONACO, C. F. L. EPA and DHA treatment protects pancreatic beta cells against palmitic acid-induced dysfunction. 2017. 84p. Thesis (Doctorate in Human Physiology) - Instituto de Ciências Biomédicas, Universidade de São Paulo, São Paulo, 2017.
\end{abstract}

Insulin secretion is stimulated by glucose, but fatty acids (FA) may influence the secretory process induced by glucose. The $\omega 3 \mathrm{FA}$ interferes in several physiological processes, and in the pancreatic islets, the $\omega 3 \mathrm{FA}$ can collaborate to decrease of lipotoxicity induced by palmitic acid.

To palmitic acid deleterious effects are attributed in several tissues, as well as in $\beta$ cells, where it promotes a change in the membrane phospholipids composition, changing the electric potential and consequently the insulin granules extrusion process. Chronic exposure of $\beta$ cells to palmitic acid is toxic, leading to a decrease in the insulin secretion response, reduction of glucose oxidation and uptake, culminating in the $\beta$-cells death. In addition, palmitic acid increases the reactive oxygen species (ROS) that in the supraphysiological concentrations will also contribute to the cell failure and death.

The ROS may come from mitochondrial activity through the nutrients metabolism, or deriving from the enzymatic complex NADPH oxidase activation, that is modulated by glucose and FA, including palmitic acid.

In contrast, the $\omega 3 \mathrm{FA}$ exerts anti-inflammatory and antioxidant effects in several systems, contributing to the improvement of lipid profile and peripheral resistance to insulin. In $\beta$ cells, the presence of $\omega 3$ FA was shown to be effective in preventing secretory damage and increased ROS, besides helping to maintain cell viability and glucose uptake in islets treated with palmitic acid, which play an important protective role in the cell $\beta$.

Keywords: Pancreatic islet. Omega-3 Fatty Acid. Palmitic acid. Insulin secretion. ROS. NADPH oxidase. Apoptosis. 


\section{1 - INTRODUÇÃO}

\section{1 - Obesidade}

A obesidade pode ser definida como acúmulo excessivo de tecido adiposo corporal, que traz prejuízos à saúde física e psicossocial (WORLD HEALTH ORGANIZATION, 2014). Trata-se de uma epidemia mundial, crescente desde a década de 90, com o avanço da chamada transição nutricional, caracterizada principalmente pela redução de doenças infecciosas e aumento de doenças crônicas não transmissíveis (JAMES, 2004; MELO et al., 2008; PALMA et al., 2014; PINHEIRO et al., 2004).

Os processos de urbanização e industrialização contribuíram para a transição demográfica e epidemiológica. Mudanças no estilo de vida, como o aumento do sedentarismo, além de dietas ricas em gordura saturada e pobres em fibras, levaram a alterações significativas na composição corporal da população (MELO et al., 2008; POPKIN; GORDON-LARSEN, 2004). É importante também considerar o papel da indústria de alimentos não só no Brasil como no mundo e, a força do marketing para o consumo destes alimentos, já que o poder econômico das empresas do segmento contribui para a atribuição de valor às marcas e aos seus produtos. Por outro lado, a redução do valor de produção e venda em grande escala destes produtos favorece mais ainda seu consumo em detrimento aos alimentos frescos e mais saudáveis (JAMES, 2004; PALMA et al., 2014; PINHEIRO et al., 2004).

O aumento da mortalidade por doenças crônicas associadas ao excesso de peso deixa claro o impacto da epidemia de obesidade não só à saúde do indivíduo, mas também aos sistemas de saúde e à economia. Atualmente cerca de 2 bilhões de adultos em todo o mundo estão acima do peso, destes, mais de meio bilhão são obesos, segundo dados da Organização Mundial da Saúde. Os riscos de doença coronariana, acidente vascular cerebral isquêmico e diabetes mellitus tipo II (DMII) estão positivamente associados ao aumento do índice de massa corporal (IMC). Os valores de normalidade do IMC para uma população adulta está na faixa 18,5-24,9 $\mathrm{kg} / \mathrm{m}^{2}$. Existe um risco aumentado com IMC entre 25,0-29,9, e risco grave para IMC acima de $30 \mathrm{~kg} / \mathrm{m}^{2}$, para estas comorbidades (ARRIETA et al., 2014; WHO, 2014). 
O sobrepeso e a obesidade apresentam alta associação com o DMII, a endocrinopatia mais prevalente no mundo, caracterizada pela hiperglicemia, fator responsável pelas inúmeras comorbidades associadas à obesidade . O DMII é uma doença multifatorial, caracterizada pela desregulação no metabolismo dos nutrientes, resultante de um defeito nos processos de produção e/ou ação e/ou secreção de insulina. A estimativa é de que 366 milhões de pessoas no mundo sejam diagnosticadas com o DMII até 2030. As complicações do DMII, micro e macrovasculares, são as mais comuns, incluindo nefropatia, cegueira e, neuropatia a qual pode levar a amputações dos membros (ARRIETA et al., 2014; SHARIFUL ISLAM et al., 2013).

$\mathrm{O}$ aumento da prevalência da obesidade em todo o mundo resultou na maior incidência de DMII e, sem dúvidas, novas estratégias farmacológicas e comportamentais para conter a progressão da doença e seus efeitos são necessárias. Portanto, o estudo da fisiopatologia do diabetes mellitus é de extrema importância tanto para ampliar o entendimento sobre sua etiologia quanto para o desenvolvimento de intervenções efetivas. Neste sentido, estudar a fisiologia das células $\beta$ pancreáticas, torna-se fundamental (JAACKS et al., 2016; JAMES et al., 2001; JAMES, 2004; POPKIN; GORDON-LARSEN, 2004).

\subsection{Fisiologia da Secreção de Insulina}

O pâncreas é uma glândula mista, responsável pela produção de enzimas digestivas (porção exócrina) que são secretadas na luz do duodeno, bem como pela produção de hormônios (porção endócrina) secretados no interstício, de onde alcançam a corrente sanguínea. A porção endócrina do pâncreas constitui $2 \%$ da massa total do órgão e é formada pelas Ilhotas de Langerhans, que são estruturas ovoides compostas por quatro tipos celulares: as células $\mathrm{A}$ ou $\alpha$, que correspondem a $25 \%$ da massa da ilhota e são responsáveis pela síntese e secreção de glucagon; as células B ou $\beta$, perfazendo $60 \%$ da massa da ilhota e responsáveis pela síntese e secreção de insulina; as células D ou $\delta$ que sintetizam e secretam somatostatina e constituem $10 \%$ da ilhota; e as células PP produtoras do polipeptídeo pancreático, que ocupam cerca de $5 \%$ da ilhota de Langerhans (AIRES, 2008; KOEPPEN, 2009). 
As células $\beta$ sintetizam, armazenam e liberam insulina conforme a demanda do organismo, mantendo a homeostase glicêmica. A insulina é um polipeptídio com duas cadeias de aminoácidos ligados por pontes dissulfeto, sintetizada no retículo endoplasmático rugoso e transportada até o complexo de Golgi, onde é empacotada em grânulos. Sua secreção é principalmente regulada por substratos energéticos, sendo a glicose o mais importante secretagogo deste hormônio (DEENEY et al., 2000; NELSON; COX, 2002).

O transporte da glicose plasmática através da membrana das células $\beta$ é feito pelo transportador de glicose-2 (GLUT-2) (MUECKLER, 1994; NEWSHOLME et al., 2010). Uma vez no interior da célula $\beta$, a glicose é fosforilada à glicose-6-fosfato pela glicoquinase, enzima que atua como fator limitante no fluxo de substratos através desta via (DEENEY et al., 2000; NEWSHOLME et al., 2010). Após uma série de fosforilações, será formado o piruvato, que em condições anaeróbicas poderá gerar lactato, mas na presença de oxigênio seguirá o fluxo da degradação completa da glicose através do Ciclo de Krebs, culminando na síntese de ATP nas mitocôndrias (NELSON; COX, 2002).

A metabolização da glicose-6-fosfato aumenta a produção de ATP e a relação ATP/ADP aumentada leva à diminuição da probabilidade de abertura dos canais para $\mathrm{K}^{+}$sensíveis ao ATP $\left(\mathrm{K}_{\mathrm{ATP}}\right)$ levando ao aumento da concentração intracelular de $\mathrm{K}^{+}$. O acúmulo de $\mathrm{K}^{+}$promove a despolarização da membrana, induzindo ao aumento da probabilidade de abertura dos canais para $\mathrm{Ca}^{2+}$ sensíveis à voltagem (CCSV), aumentando o influxo deste íon. $\mathrm{O}$ aumento do $\mathrm{Ca}^{2+}$ intracelular é um dos principais responsáveis pela ativação inicial da exocitose dos grânulos de insulina (ASHCROFT; RORSMAN, 1990; DEENEY et al., 2000) além de favorecer a ativação de diferentes isoformas da fosfolipase C (PLC) a qual promove a hidrólise de fosfolípides de membrana, gerando 1,4,5 inositol trifosfato $\left(\mathrm{IP}_{3}\right)$ e diacilglicerol (DAG). O IP 3 estimula o efluxo de $\mathrm{Ca}^{2+}$ do retículo endoplasmático, aumentando ainda mais sua concentração no citosol. O DAG age como um potente ativador da proteína quinase C (PKC), responsável pela fosforilação de proteínas envolvidas no processo de exocitose. A ativação da adenilato ciclase (AC), leva à ativação da proteína quinase A (PKA) através da formação de AMPc, que participa do processo de exocitose, agindo nos processos de síntese protéica da célula (DEENEY et al., 2000; PINTON et al., 2004). A figura 1 esquematiza todo este processo. 


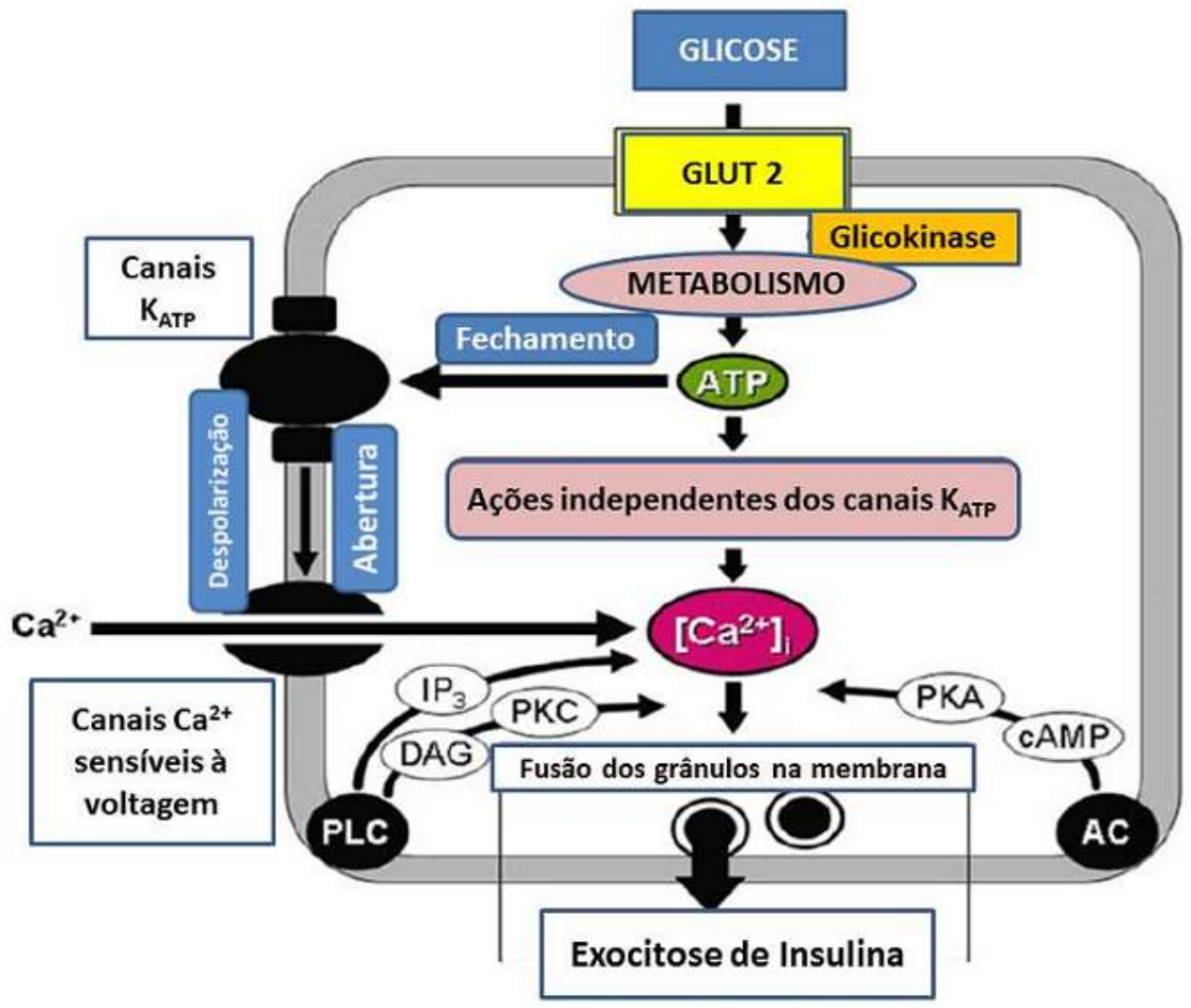

Figura 1 - Representação dos mecanismos envolvidos na secreção de insulina estimulada pela glicose em células $\beta$ pancreáticas. Fonte: (NEWSHOLME et al., 2010).

\section{3 - Ácidos Graxos, Lipotoxicidade e Secreção de Insulina}

Os efeitos dos nutrientes sobre as células $\beta$ podem ser diferentes, de acordo com o tempo de exposição: agudo ou crônico. Concentrações elevadas de glicose e ácidos graxos (AG) estimulam a secreção de insulina agudamente, enquanto que a exposição crônica pode levar a glicotoxicidade e lipotoxicidade, respectivamente (CARPINELLI et al., 2002; HABER et al., 2003; HABER et al., 2006; MARTINS et al., 2004).

Glicotoxicidade e lipotoxicidade induzem a redução da resposta secretória de insulina pelas células $\beta$ devido à alteração de diversos mecanismos tais como fluidez da membrana plasmática, palmitoilação de proteínas, formação de ceramidas, disfunção 
mitocondrial, estresse de retículo endoplasmático, autofagia e apoptose (BRIAUD et al., 2001; HIGA et al., 2006; LANG et al., 2011; LUPI et al., 2002a; MAEDLER et al., 2001; POITOUT et al., 2004; SUMMERS, 2006).

Um dos mecanismos envolvidos no processo de lipotoxicidade é a ativação do fator de transcrição SREBP-1 (proteína de ligação ao elemento regulador de esterol 1), que é um fator regulador de enzimas lipogênicas. A ativação deste fator de transcrição é controlada por nutrientes da dieta (principalmente glicose e AG) e pode interferir na maquinaria exocitótica, prejudicando a extrusão dos grânulos de insulina (DIRAISON et al., 2004; DIRAISON et al., 2008; TAKAHASHI et al., 2005; YAHAGI et al., 1999). $\mathrm{O}$ aumento da glicose também leva à hidrolise de AG presentes nos fosfolípides de membrana, que se tornam mais suscetíveis à peroxidação lipídica (COHEN et al., 2015).

O potencial insulinossecretório dos AG varia de acordo com: o comprimento da cadeia, o grau de insaturação e o tempo de exposição das ilhotas aos mesmos (STEIN et al., 1997). Os principais efeitos dos AG estão relacionados ao fato destes afetarem a composição da membrana plasmática, e consequentemente sua função, alterando a translocação de transportadores de glicose, a fluidez da membrana, a permeabilidade a íons, a afinidade do receptor de insulina, a expressão gênica e a atividade enzimática (HABER et al., 2003; HABER et al., 2006; MARTINS et al., 2004; ZHOU; GRILL, 1995; ZHOU et al., 1996).

As principais diferenças nos efeitos desencadeados pelos AG saturados e insaturados dizem respeito às taxas de metabolismo e a forma de estoques dos mesmos, já que os AG saturados são estocados principalmente nas formas de monoacilgliceróis, diacilgliceróis e ceramidas, os quais estão intimamente relacionados ao aumento da expressão de citocinas pró-inflamatórias no tecido adiposo, induzindo resistência à insulina neste tecido, além de induzir lipotoxicidade em monócitos por ativação da cicloxigenase 2 (COX2). Em contrapartida, AG monoinsaturados são estocados na forma de triacilgliceróis e não possuem os mesmos efeitos (DOMMELS et al., 2003; KEANE et al., 2011, LUO; WANG, 2011; MAEDLER et al., 2001; ORTSATER, 2011).

Quimicamente, os AG são cadeias hidrocarbônicas constituídas por um grupo carbonil e um grupo metil terminal, sendo que o comprimento da cadeia carbônica, a presença de insaturação e a localização de duplas ligações que definem as características dos mesmos (NELSON; COX, 2002). 
O ácido palmítico é o ácido graxo saturado mais encontrado em animais, plantas e microrganismos, sua estrutura é formada por 16 carbonos e nenhuma dupla ligação (MAEDLER et al., 2001; STEIN et al., 1997). Está amplamente distribuído em produtos consumidos em grande escala, como carnes, queijos e manteigas. Ao ácido palmítico são atribuídos efeitos deletérios em vários tecidos, como nas células $\beta$, onde alteram a composição dos fosfolípides de membrana, alterando o potencial elétrico da mesma e consequentemente o processo de extrusão dos grânulos de insulina (Olofsson et al., 2007; GWIAZDA et al., 2009; LIANG et al., 2011; OLOFSSON et al., 2007).

A exposição crônica das células $\beta$ ao ácido palmítico é tóxica, provocando diminuição da resposta secretória de insulina estimulada pela glicose e apoptose das células $\beta$ pancreáticas (BRIAUD et al., 2001; CARPINELLI et al., 2002; KELPE et al., 2003; LUCENA et al., 2015; POITOUT et al., 2004). A lipotoxicidade ocorre por diversos mecanismos, dentre eles, podemos citar a síntese de ceramidas, uma vez que já foi observado que a inibição da síntese das mesmas, atenua o dano causado às ilhotas pancreáticas (LANG et al., 2011; LUPI et al., 2002b; MANUKIAN et al., 2015; SUMMERS, 2006). Além disso, o ácido palmítico altera a regulação das chaperonas, que são proteínas envolvidas no enovelamento proteico (OYADOMARI et al., 2002). Ambas, a síntese de ceramidas e a regulação de chaperonas estão envolvidas num processo chamado estresse de retículo endoplasmático (CNOP et al., 2008; CNOP et al., 2010; CNOP et al., 2012; CUNHA et al., 2008; EIZIRIK et al., 2008; EIZIRIK; CNOP, 2010).

O estresse de retículo endoplasmático ocorre pelo acúmulo de proteínas mal formadas ou mal dobradas no lúmen do retículo, que interferirão no processo secretório da insulina ou na própria síntese da insulina (CNOP et al., 2008; CNOP et al., 2010; CNOP et al., 2012; CUNHA et al., 2008; EIZIRIK et al., 2008; EIZIRIK; CNOP, 2010). O acúmulo destas proteinas desencadeia um mecanismo chamado de resposta da proteina mal dobrada (unfolded protein response - UPR) que é ativado para garantir a normalização do processo de síntese e dobramento das proteínas. Este mecanismo envolve: 1) aumento na expressão de chaperonas, garantindo o dobramento e prevenindo a agregação proteica; 2) atenuação da tradução, evitando o acúmulo de proteínas mal dobradas; 3) degradação de proteínas mal dobradas; 4) ativação da apoptose, quando o acúmulo de proteínas ultrapassa a capacidade da UPR. Estes processos são desencadeados por uma cascata de sinalização intracelular promovida 
pelas proteínas: enzima que requer inositol 1 (IRE 1), quinase do retículo PKR-like (PERK) e fator de ativação de transcrição (ATF 6). Em estado basal, estas proteínas estão inibidas pela ligação com a proteínas de ligação (BiP) (OYADOMARI et al., 2002).

Em contrapartida aos efeitos deletérios do ácido palmítico, ao tratamento crônico com AG $\omega 3$ têm sido atribuídos benefícios em vários processos patológicos, como a melhora do perfil lipídico, prevenção de doença coronariana e infarto do miocárdio (HARRIS et al., 1997; NETTLETON, 1995; SKERRETT; HENNEKENS, 2003), melhora da resposta imune (HWANG, 2000; SIMOPOULOS, 2002), prevenção de câncer de mama e próstata (DE DECKERE, 1999; FUKUI et al., 2013; ROSE, 1997) e câncer de cólon (DOMMELS et al., 2003).

O $\omega 3$, cuja estrutura química é mais simples, é o $\alpha$-linolênico (ALA) o qual pode ser sintetizado a partir do $\alpha$-linoleico (LA). Porém, mamíferos não possuem a enzima necessária para síntese de ALA a partir de LA, fazendo com que o ALA seja classificado como um AG essencial na alimentação humana. O ALA é o 03 mais presente na dieta ocidental (CALDER, 2003; CALDER; YAQOOB, 2009). Os outros AG $\omega$-3 são eicosapentaenóico (EPA) e o docosahexaenóico (DHA), de origem marinha e que são sintetizados no fitoplâncton e consumidos por peixes, moluscos e crustáceos, sendo estes animais fontes de $\omega 3$ na alimentação humana (JUMP, 2002; NETTLETON, 1995). Importante salientar que o corpo humano é capaz de converter apenas $5 \%$ de ALA em EPA, tornando a ingestão alimentar do segundo, também essencial (ELLULU et al., 2015; JUMP, 2002). A estrutura química dos ácidos graxos $\omega 3$ está representada na figura 2. 


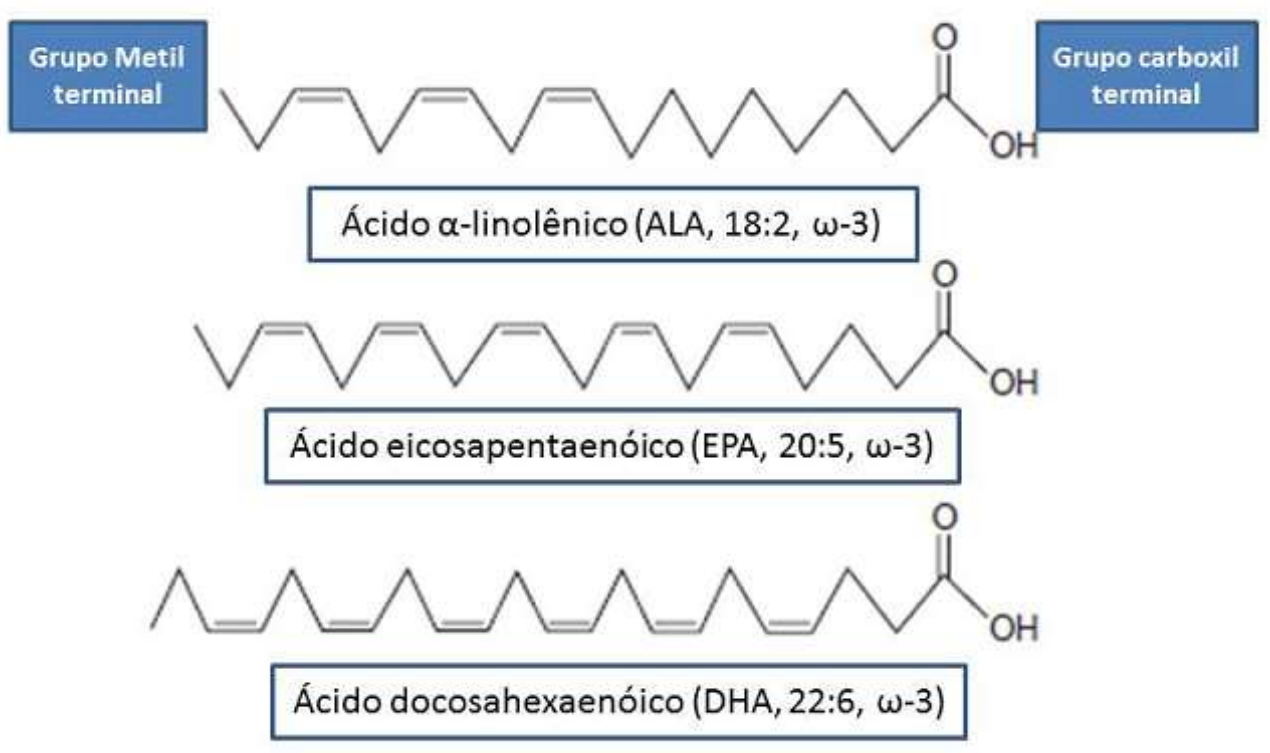

Figura 2 - Estrutura química dos ácidos graxos ômega-3 Fonte: (WANG; CHAN, 2015).

O aumento na ingestão de peixes resulta em maiores concentrações de EPA e DHA no plasma, células e tecidos, e a presença destes AG nas membranas celulares influencia o metabolismo de eicosanoides com repercussão positiva na fisiologia de diversos sistemas (BURDGE; CALDER, 2005; CALDER, 2006a;b; CARPENTIER et al., 2006; YAQOOB; CALDER, 2003).

Os eicosanoides estão envolvidos no controle de muitos processos fisiológicos, como a reação inflamatória (RANG, 2004). São compostos derivados da oxigenação do ácido araquidônico (AA) e surgem da atividade de duas enzimas: ciclooxigenase $(\mathrm{COX})$, responsável pela produção de prostanóides, como prostaglandinas (PG) e tromboxanos (TX;) e lipooxigenase (LOX), responsável pela produção de leucotrienos (LT) (CALDER, 2006a; DE PABLO; CIENFUEGOS, 2000; JUMP, 2002).

O $\omega 3$ é um potente inibidor da COX, modulando o metabolismo do AA. Nas dietas ricas em $\omega 3$, parece haver uma redução da $\mathrm{COX} 2$, devido à função inibitória do $\omega 3$ sobre a síntese de $\mathrm{PGE}_{2}$ a partir de AA (DOMMELS et al., 2003). Dietas ricas em LA aumentam a disponibilidade de AA e consequentemente alteram o metabolismo de eicosanoides. Já a suplementação com óleo de peixe resulta em substituição de AA por EPA nos fosfolípides de membrana, levando à diminuição da produção de mediadores derivados de AA, exercendo desta forma um efeito anti-inflamatório potente. O EPA e o 
DHA competem com o AA pela COX, ocupando os sítios disponíveis (figura 3). Além disso, a incorporação de AG $\omega 3$ à membrana pode alterar suas propriedades físicoquímicas, a atividade de receptores e sinalização celular (BURDGE; CALDER, 2005).

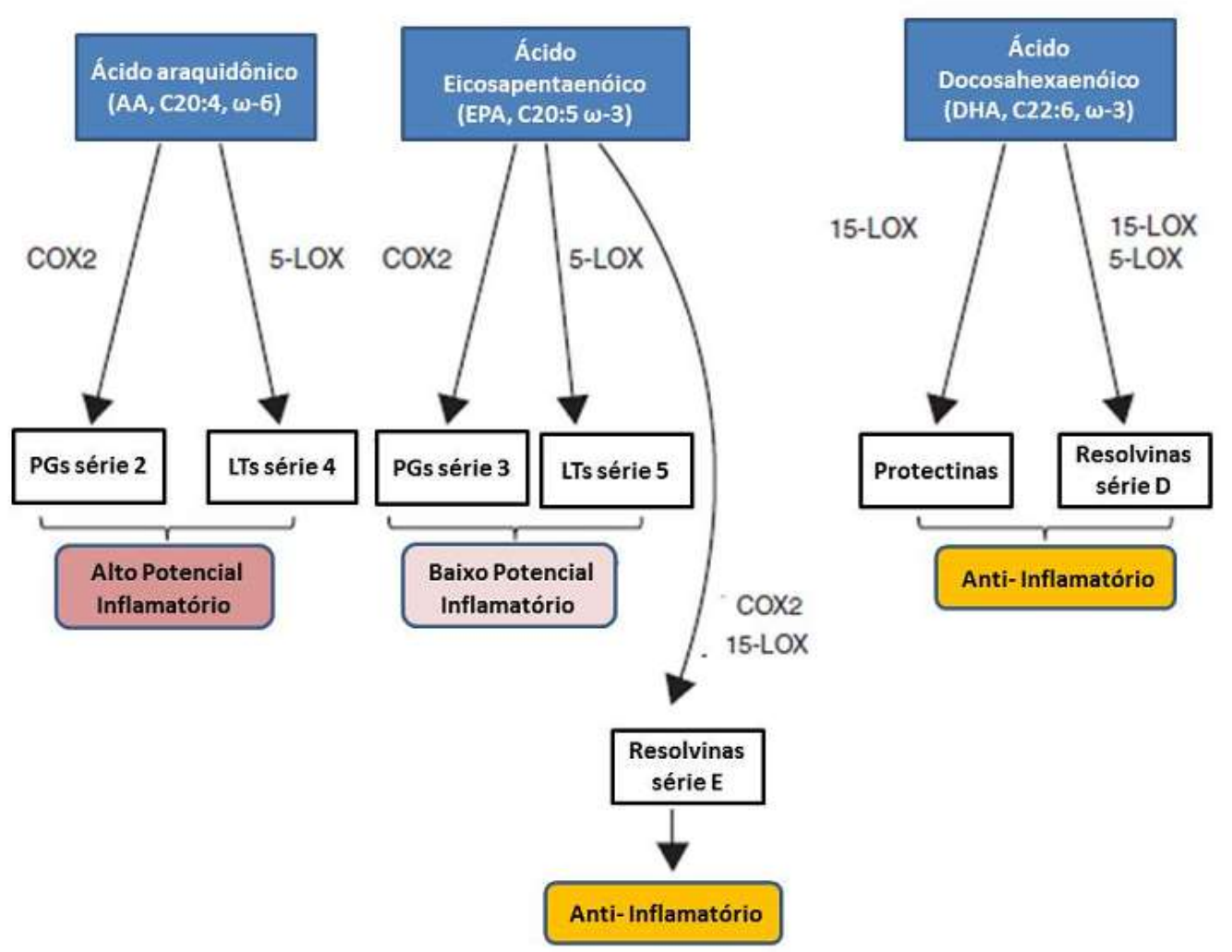

Figura 3 - Modulação da formação de mediadores inflamatórios por ácidos graxos. Fonte: (WANG; CHAN, 2015).

Estudos in vivo mostram que animais com deficiência de $\omega 3$ apresentam desordens metabólicas importantes, como prejuízo na sinalização insulínica (AGASCIOGLU et al., 2007; CANCELAS et al., 2007; SENER et al., 2006) caracterizando resistência periférica à insulina (CANCELAS et al., 2007) e alterações no processo de oxidação da glicose (OGUZHAN et al., 2006; SIRIWARDHANA et al., 2012), além de alteração na expressão de genes envolvidos na oxidação e síntese de lipídios, bem como genes que modulam a resposta inflamatória (CALDER, 2006a;b). A 
infusão de AG $\omega 3$ nestes animais melhorou os parâmetros metabólicos (RICHARD et al., 2008; SIRIWARDHANA et al., 2012).

Apesar dos efeitos benéficos atribuídos ao $\omega 3$, poucos estudos testaram seu efeito quando combinado ao ácido palmítico, observando melhora da secreção de insulina em ilhotas isoladas de camundongos (KATO et al., 2008) e em linhagem celular INS-1 (SHAO et al., 2010).

\section{4 - Espécies Reativas de Oxigênio}

Um dos fatores que pode levar à disfunção da célula $\beta$ é a produção excessiva ou continuada de espécies reativas de oxigênio e nitrogênio (EROs e ERNs), que podem alterar a integridade e função de macromoléculas como DNA, proteínas e lipídios, contribuindo para a patogênese de doenças neurodegenerativas, envelhecimento, processos inflamatórios, reações imunológicas, câncer e diabetes. O dano provocado pelas EROs é determinado não somente pela geração das mesmas, mas também pelo estado antioxidante da célula, sendo que os tecidos apresentam diferenças na suscetibilidade aos danos citotóxicos e na expressão dos agentes antioxidantes. Porém, em pequenas quantidades, as EROs agem como sinalizadores intracelulares em diversos tecidos, inclusive atuando como sinalizadores da síntese e secreção de insulina (BINDOKAS et al., 2003; PI et al., 2007). Sabe-se que EROs e ERNs são componentes da sinalização celular de processos de regulação do tônus vascular, ativação de fatores envolvidos na hipóxia, além de proliferação, diferenciação e migração celular (WEIDINGER; KOZLOV, 2015).

A mitocôndria é a maior fonte de EROs a partir do metabolismo dos nutrientes, principalmente através dos complexos I e III, sendo que a disfunção mitocondrial é a principal responsável pelo aumento na geração de EROs associado ao diabetes (BRAND et al., 2004; WEIDINGER; KOZLOV, 2015). Porém, outras fontes celulares produzem EROS, dentre elas o sistema NADPH oxidase (BABIOR, 1999; JONES et al., 2000; OLIVEIRA et al., 2003).

A NADPH oxidase é um complexo enzimático (figura 4) envolvido na ação antipatogênica de neutrófilos, sendo que a habilidade em produzir EROs é vital para defesa contra infecções (JONES et al., 2000). A enzima é formada por duas subunidades situadas na membrana plasmática: gp91 ${ }^{\text {phox }}$ e p22 phox , que formam o citocromo b558 e 
constituem o centro redox da enzima. Além delas, existem subunidades presentes no citosol: $\mathrm{p} 67^{\text {phox }}, \mathrm{p} 40^{\text {phox }}, \mathrm{p} 47^{\text {phox }}$ e Rac. A ativação do complexo inicia-se com a fosforilação da subunidade $\mathrm{p} 47^{\text {phox }}$, e translocação das subunidades citosólicas para a membrana, formando o complexo ativo, o qual é responsável pela geração de ânion superóxido $\left(\mathrm{O}_{2}{ }^{\bullet-}\right)$ (BABIOR, 1999; JONES et al., 2000).

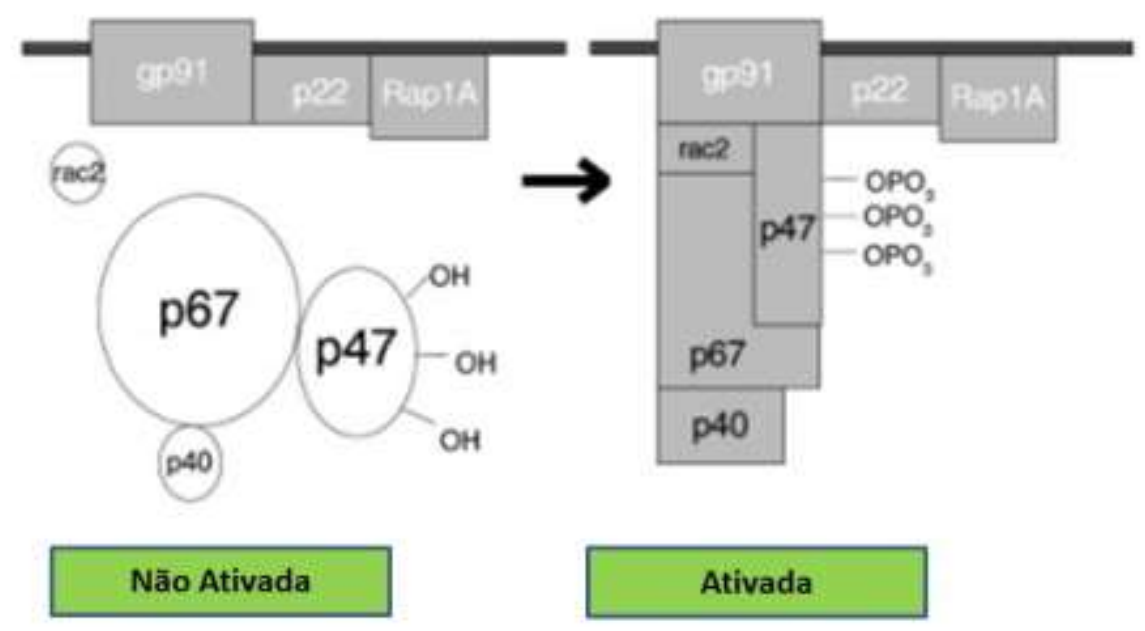

Figura 4 - Representação das subunidades da NADPH oxidase na forma inativa e na forma ativada, com migração das subunidades citosólicas junto às subunidades de membrana. Fonte: (BABIOR, 1999).

O complexo NADPH oxidase é reconhecido como importante fonte de EROs em fagócitos, células endoteliais, células vasculares musculares lisas, células da tireóide, fibroblastos, linfócitos e osteoclastos (BABIOR, 1999). Nosso grupo mostrou que ilhotas pancreáticas também expressam os componentes da NADPH oxidase (OLIVEIRA et al., 2003), sendo que sua atividade e expressão nestas células é modulada pela glicose e por alguns AG, como ácidos oleico e palmítico (GRACIANO et al., 2011a;b; GRACIANO et al., 2013; MORGAN et al., 2007; MORGAN et al., 2009; SANTOS et al., 2011; SCHONFELD; WOJTCZAK, 2008).

Além disso, o ácido palmítico ativa a NADPH oxidase em células INS-1E, aumentando o conteúdo de EROs agudamente, em diferentes concentrações de glicose (GRACIANO et al., 2011a;b; SANTOS et al., 2011). Da mesma forma, o ácido oleico 
aumentou a expressão de $447^{\text {phox }}$, gp91 phox e PKC com aumento no conteúdo de EROs, sugerindo também uma possível ação regulatória sobre a NADPH oxidase em ilhotas pancreáticas e em células INS-1E (SANTOS et al., 2011).

A geração de EROs de diferentes fontes (mitocondriais ou não), é um outro mecanismo envolvido na lipotoxicidade. Quando a geração de EROs ultrapassa os limites da defesa antioxidante, as mesmas tornam-se possíveis agressores da célula $\beta$, contribuindo para sua disfunção e morte (GEHRMANN et al., 2010).

Recentemente, mostramos que a suplementação de ratos Wistar com óleo de peixe por 60 dias, reduziu o conteúdo de EROs e a expressão proteica das subunidades gp91 ${ }^{\text {phox }}$ e p47 $7^{\text {phox }}$ nas ilhotas pancreáticas (LUCENA et al., 2015). De forma semelhante, observou-se uma redução no conteúdo de EROs, ao realizarem knockdown da $47^{\text {phox }}$ em ilhotas pancreáticas (MORGAN et al., 2007).

A redução do conteúdo de EROs, até certo ponto, parece ser benéfico para as ilhotas. Foi visto que ratos diabéticos apresentam maior conteúdo de EROs quando comparados aos animais normais, e isso pode estar associado à maior ativação da NADPH oxidase, já que os ratos diabéticos apresentam maior expressão das subunidades gp91 $1^{\text {phox }}$ e p47 phox $\quad$ (SYED et al., 2011). Por outro lado, vimos que a suplementação de ratos normais com óleo de peixe, aumentou a expressão proteica da enzima SOD1 e SOD2 nas ilhotas pancreáticas, indicando um possível aumento na defesa antioxidante das ilhotas (LUCENA et al., 2015). Da mesma maneira, foi observado um aumento na atividade da SOD plasmática em ratos wistar suplementados por 30 dias com óleo de peixe (ERDOGAN et al., 2004) e um aumento na atividade da SOD e da catalase em hepatócitos de camundongos tratados com dieta rica em óleo de peixe por 10 semanas (WANG et al., 2004). 


\section{CONCLUSÕES}

Os AG $\omega 3$ (EPA+DHA) foram capazes de prevenir o dano secretório, reduzir o conteúdo de EROs, manter a viabilidade celular e a captação de glicose das ilhotas pancreáticas tratadas concomitantemente com ácido palmítico por 48 horas.

Fica evidente o importante papel protetor dos AG $\omega-3$ na prevenção da disfunção e morte celular induzidas pelo ácido palmítico. 


\section{REFERÊNCIAS*}

AGASCIOGLU, E. et al. Phospholipid fatty acid pattern and D-glucose metabolism in muscles from omega3 fatty acid-depleted rats. Biochimie, v. 89, n. 3, p. 374-382, Mar 2007. ISSN 0300-9084. Disponível em: http://www.ncbi.nlm.nih.gov/pubmed/17084500 >.

AIRES, M. D. M. Fisiologia. Rio de Janeiro: Guanabara Koogan, 2008.

AMMON, H. P. et al. Islet glutathione and insulin release. Diabetes, v. 29, n. 10, p. 830-834, Oct 1980. ISSN 0012-1797. Disponível em: < https://www.ncbi.nlm.nih.gov/pubmed/7002664 >.

ARRIETA, F. et al. Estimation of the economic and health impact of complications of type 2 diabetes mellitus in the autonomous community of Madrid (Spain). Endocrinol Nutr, v. 61, n. 4, p. 193-201, Apr 2014. ISSN 1579-2021. Disponível em: < http://www.ncbi.nlm.nih.gov/pubmed/24440211 >.

ASHCROFT, F. M.; RORSMAN, P. ATP-sensitive K+ channels: a link between B-cell metabolism and insulin secretion. Biochem Soc Trans, v. 18, n. 1, p. 109-111, Feb 1990. ISSN 0300-5127. Disponível em: < http://www.ncbi.nlm.nih.gov/pubmed/2185070 >.

BABIOR, B. M. NADPH oxidase: an update. Blood, v. 93, n. 5, p. 1464-1476, Mar 1999. ISSN 0006-4971. Disponível em: http://www.ncbi.nlm.nih.gov/pubmed/10029572 >.

BEEHARRY, N.; CHAMBERS, J. A.; GREEN, I. C. Fatty acid protection from palmitic acid-induced apoptosis is lost following PI3-kinase inhibition. Apoptosis, v. 9, n. 5, p. 599-607, Sep 2004. ISSN 1360-8185. Disponível em: < http://www.ncbi.nlm.nih.gov/pubmed/15314288 >.

BINDOKAS, V. P. et al. Visualizing superoxide production in normal and diabetic rat islets of Langerhans. J Biol Chem, v. 278, n. 11, p. 9796-9801, Mar 2003. ISSN 00219258. Disponível em: < http://www.ncbi.nlm.nih.gov/pubmed/12514170 >.

*De acordo com: ASSOCIAÇÃO BRASILEIRA DE NORMAS TÉCNICAS. NBR 6023: informação e documentação: referências: elaboração. Rio de Janeiro, 2002. 
BRAND, M. D. et al. Mitochondrial superoxide and aging: uncoupling-protein activity and superoxide production. Biochem Soc Symp, n. 71, p. 203-213, 2004. ISSN 00678694. Disponível em: < http://www.ncbi.nlm.nih.gov/pubmed/15777023 >.

BRIAUD, I. et al. Lipotoxicity of the pancreatic beta-cell is associated with glucosedependent esterification of fatty acids into neutral lipids. Diabetes, v. 50, n. 2, p. 315321, Feb 2001. ISSN 0012-1797. Disponível em: < http://www.ncbi.nlm.nih.gov/pubmed/11272142 >.

BULTEAU, A. L.; IKEDA-SAITO, M.; SZWEDA, L. I. Redox-dependent modulation of aconitase activity in intact mitochondria. Biochemistry, v. 42, n. 50, p. 14846-14855, Dec 2003. ISSN 0006-2960. Disponível em: < https://www.ncbi.nlm.nih.gov/pubmed/14674759 >.

BURDGE, G. C.; CALDER, P. C. Conversion of alpha-linolenic acid to longer-chain polyunsaturated fatty acids in human adults. Reprod Nutr Dev, v. 45, n. 5, p. 581-597, 2005 Sep-Oct 2005. ISSN 0926-5287. Disponível em: < http://www.ncbi.nlm.nih.gov/pubmed/16188209 >.

CALDER, P. C. Polyunsaturated fatty acids and cytokine profiles: a clue to the changing prevalence of atopy? Clin Exp Allergy, v. 33, n. 4, p. 412-415, Apr 2003. ISSN 0954-7894. Disponível em: < http://www.ncbi.nlm.nih.gov/pubmed/12680853 >.

n-3 polyunsaturated fatty acids, inflammation, and inflammatory diseases. Am J Clin Nutr, v. 83, n. 6 Suppl, p. 1505S-1519S, Jun 2006a. ISSN 0002-9165. Disponível em: < http://www.ncbi.nlm.nih.gov/pubmed/16841861 >.

Polyunsaturated fatty acids and inflammation. Prostaglandins Leukot Essent Fatty Acids, v. 75, n. 3, p. 197-202, Sep 2006b. ISSN 0952-3278. Disponível em: < http://www.ncbi.nlm.nih.gov/pubmed/16828270 >.

CALDER, P. C.; YAQOOB, P. Omega-3 polyunsaturated fatty acids and human health outcomes. Biofactors, v. 35, n. 3, p. 266-272, 2009 May-Jun 2009. ISSN 0951-6433. Disponível em: < http://www.ncbi.nlm.nih.gov/pubmed/19391122 >.

CANCELAS, J. et al. Glucose intolerance associated to insulin resistance and increased insulin secretion in rats depleted in long-chain omega3 fatty acids. Horm Metab Res, v. 39, n. 11, p. 823-825, Nov 2007. ISSN 0018-5043. Disponível em: < http://www.ncbi.nlm.nih.gov/pubmed/17992638 >.

CARLSSON, C.; BORG, L. A.; WELSH, N. Sodium palmitate induces partial mitochondrial uncoupling and reactive oxygen species in rat pancreatic islets in vitro. 
Endocrinology, v. 140, n. 8, p. 3422-3428, Aug 1999. ISSN 0013-7227. Disponível em: < http://www.ncbi.nlm.nih.gov/pubmed/10433196 >.

CARPENTIER, Y. A.; PORTOIS, L.; MALAISSE, W. J. n-3 fatty acids and the metabolic syndrome. Am J Clin Nutr, v. 83, n. 6 Suppl, p. 1499S-1504S, Jun 2006. ISSN 0002-9165. Disponível em: < http://www.ncbi.nlm.nih.gov/pubmed/16841860 >.

CARPINELLI, A. R. et al. Insulin secretion induced by palmitate--a process fully dependent on glucose concentration. Diabetes Metab, v. 28, n. 6 Pt 2, p. 3S37-44; discussion 3S108-12, Dec 2002. ISSN 1262-3636. Disponível em: < https://www.ncbi.nlm.nih.gov/pubmed/12688632 >.

CNOP, M. et al. An update on lipotoxic endoplasmic reticulum stress in pancreatic beta-cells. Biochem Soc Trans, v. 36, n. Pt 5, p. 909-915, Oct 2008. ISSN 0300-5127. Disponível em: < http://www.ncbi.nlm.nih.gov/pubmed/18793160 >.

Causes and cures for endoplasmic reticulum stress in lipotoxic $\beta$-cell dysfunction. Diabetes Obes Metab, v. 12 Suppl 2, p. 76-82, Oct 2010. ISSN 14631326. Disponível em: < http://www.ncbi.nlm.nih.gov/pubmed/21029303 >.

Mechanisms of pancreatic beta-cell death in type 1 and type 2 diabetes: many differences, few similarities. Diabetes, v. 54 Suppl 2, p. S97-107, Dec 2005. ISSN 0012-1797. Disponível em: < http://www.ncbi.nlm.nih.gov/pubmed/16306347 >.

CNOP, M. et al. Endoplasmic reticulum stress, obesity and diabetes. Trends Mol Med, v. 18, n. 1, p. 59-68, Jan 2012. ISSN 1471-1499X. Disponível em: < http://www.ncbi.nlm.nih.gov/pubmed/21889406 >.

COHEN, G. et al. Beta cell response to nutrient overload involves phospholipid remodelling and lipid peroxidation. Diabetologia, Mar 2015. ISSN 1432-0428. Disponível em: < http://www.ncbi.nlm.nih.gov/pubmed/25810039 >.

CUNHA, D. A. et al. Initiation and execution of lipotoxic ER stress in pancreatic betacells. J Cell Sci, v. 121, n. Pt 14, p. 2308-2318, Jul 2008. ISSN 0021-9533. Disponível em: < http://www.ncbi.nlm.nih.gov/pubmed/18559892 >.

DE DECKERE, E. A. Possible beneficial effect of fish and fish n-3 polyunsaturated fatty acids in breast and colorectal cancer. Eur J Cancer Prev, v. 8, n. 3, p. 213-221, Jul 1999. ISSN 0959-8278. Disponível em: < http://www.ncbi.nlm.nih.gov/pubmed/10443950 >. 
DE PABLO, M. A.; CIENFUEGOS, G. Modulatory effects of dietary lipids on immune system functions. Immunol Cell Biol, v. 78, n. 1, p. 31-39, Feb 2000. ISSN 0818-9641. Disponível em: < http://www.ncbi.nlm.nih.gov/pubmed/10651927 >.

DEENEY, J. T.; PRENTKI, M.; CORKEY, B. E. Metabolic control of beta-cell function. Semin Cell Dev Biol, v. 11, n. 4, p. 267-275, Aug 2000. ISSN 1084-9521. Disponível em: < http://www.ncbi.nlm.nih.gov/pubmed/10966860 >.

DIRAISON, F. et al. Over-expression of sterol-regulatory-element-binding protein-1c (SREBP1c) in rat pancreatic islets induces lipogenesis and decreases glucose-stimulated insulin release: modulation by 5-aminoimidazole-4-carboxamide ribonucleoside (AICAR). Biochem J, v. 378, n. Pt 3, p. 769-778, Mar 2004. ISSN 1470-8728. Disponível em: < http://www.ncbi.nlm.nih.gov/pubmed/14690455 >.

SREBP1 is required for the induction by glucose of pancreatic beta-cell genes involved in glucose sensing. J Lipid Res, v. 49, n. 4, p. 814-822, Apr 2008. ISSN 00222275. Disponível em: < http://www.ncbi.nlm.nih.gov/pubmed/18178930 >.

DOMMELS, Y. E. et al. The role of cyclooxygenase in n-6 and n-3 polyunsaturated fatty acid mediated effects on cell proliferation, PGE(2) synthesis and cytotoxicity in human colorectal carcinoma cell lines. Carcinogenesis, v. 24, n. 3, p. 385-392, Mar 2003. ISSN 0143-3334. Disponível em: http://www.ncbi.nlm.nih.gov/pubmed/12663496 >.

EITEL, K. et al. [Apoptosis induced by free fatty acids]. Med Klin (Munich), v. 98, n. 5, p. 248-252, Apr 2003. ISSN 0723-5003. Disponível em: < http://www.ncbi.nlm.nih.gov/pubmed/12721668 >.

EIZIRIK, D. L.; CARDOZO, A. K.; CNOP, M. The role for endoplasmic reticulum stress in diabetes mellitus. Endocr Rev, v. 29, n. 1, p. 42-61, Feb 2008. ISSN 0163769X. Disponível em: < http://www.ncbi.nlm.nih.gov/pubmed/18048764 >.

EIZIRIK, D. L.; CNOP, M. ER stress in pancreatic beta cells: the thin red line between adaptation and failure. Sci Signal, v. 3, n. 110, p. pe7, 2010. ISSN 1937-9145. Disponível em: 〈 http://www.ncbi.nlm.nih.gov/pubmed/20179270 >.

EL-ASSAAD, W. et al. Saturated fatty acids synergize with elevated glucose to cause pancreatic beta-cell death. Endocrinology, v. 144, n. 9, p. 4154-4163, Sep 2003. ISSN 0013-7227. Disponível em: < http://www.ncbi.nlm.nih.gov/pubmed/12933690 >.

ELLULU, M. S. et al. Role of fish oil in human health and possible mechanism to reduce the inflammation. Inflammopharmacology, Feb 2015. ISSN 1568-5608. Disponível em: < http://www.ncbi.nlm.nih.gov/pubmed/25676565 >. 
ERDOGAN, H. et al. Effect of fish oil supplementation on plasma oxidant/antioxidant status in rats. Prostaglandins Leukot Essent Fatty Acids, v. 71, n. 3, p. 149-152, Sep 2004. ISSN 0952-3278. Disponível em: http://www.ncbi.nlm.nih.gov/pubmed/15253883 >.

FUKUI, M. et al. EPA, an omega-3 fatty acid, induces apoptosis in human pancreatic cancer cells: role of ROS accumulation, caspase- 8 activation, and autophagy induction. J Cell Biochem, v. 114, n. 1, p. 192-203, Jan 2013. ISSN 1097-4644. Disponível em: < http://www.ncbi.nlm.nih.gov/pubmed/22903547 >. ;

GEHRMANN, W.; ELSNER, M.; LENZEN, S. Role of metabolically generated reactive oxygen species for lipotoxicity in pancreatic $\beta$-cells. Diabetes Obes Metab, v. 12 Suppl 2, p. 149-158, Oct 2010. ISSN 1463-1326. Disponível em: < http://www.ncbi.nlm.nih.gov/pubmed/21029312 >.

GRACIANO, M. F. et al. NAD $(\mathrm{P}) \mathrm{H}$ oxidase participates in the palmitate-induced superoxide production and insulin secretion by rat pancreatic islets. J Cell Physiol, v. 226, n. 4, p. 1110-1117, Apr 2011. ISSN 1097-4652. Disponível em: < http://www.ncbi.nlm.nih.gov/pubmed/20857410 >.

Regulation of insulin secretion and reactive oxygen species production by free fatty acids in pancreatic islets. Islets, v. 3, n. 5, p. 213-223, 2011 Sep-Oct 2011. ISSN 1938-2022. Disponível em: < https://www.ncbi.nlm.nih.gov/pubmed/21750413 >.

Evidence for the involvement of GPR40 and NADPH oxidase in palmitic acidinduced superoxide production and insulin secretion. Islets, v. 5, n. 4, p. 139-148, 2013 Jul-Aug 2013. ISSN 1938-2022. Disponível em: < https://www.ncbi.nlm.nih.gov/pubmed/23817296 >.

GWIAZDA, K. S. et al. Effects of palmitate on ER and cytosolic Ca2+ homeostasis in beta-cells. Am J Physiol Endocrinol Metab, v. 296, n. 4, p. E690-701, Apr 2009. ISSN 0193-1849. Disponível em: 〈 http://www.ncbi.nlm.nih.gov/pubmed/19141690 >.

HABER, E. P. et al. New insights into fatty acid modulation of pancreatic beta-cell function. Int Rev Cytol, v. 248, p. 1-41, 2006. ISSN 0074-7696. Disponível em: < https://www.ncbi.nlm.nih.gov/pubmed/16487789 >.

Pleiotropic effects of fatty acids on pancreatic beta-cells. J Cell Physiol, v. 194, n. 1, p. 1-12, Jan 2003. ISSN 0021-9541. Disponível em: < https://www.ncbi.nlm.nih.gov/pubmed/12447984 >. 
HARRIS, W. S. et al. N-3 fatty acids and chylomicron metabolism in the rat. J Lipid Res, v. 38, n. 3, p. 503-515, Mar 1997. ISSN 0022-2275. Disponível em: < http://www.ncbi.nlm.nih.gov/pubmed/9101431 >.

HIGA, M. et al. Protein kinase B/Akt signalling is required for palmitate-induced betacell lipotoxicity. Diabetes Obes Metab, v. 8, n. 2, p. 228-233, Mar 2006. ISSN 14628902. Disponível em: < http://www.ncbi.nlm.nih.gov/pubmed/16448528 >.

HOPPA, M. B. et al. Chronic palmitate exposure inhibits insulin secretion by dissociation of $\mathrm{Ca}(2+)$ channels from secretory granules. Cell Metab, v. 10, n. 6, p. 455-465, Dec 2009. ISSN 1932-7420. Disponível em: < http://www.ncbi.nlm.nih.gov/pubmed/19945403 >.

HWANG, D. Fatty acids and immune responses--a new perspective in searching for clues to mechanism. Annu Rev Nutr, v. 20, p. 431-456, 2000. ISSN 0199-9885. Disponível em: < http://www.ncbi.nlm.nih.gov/pubmed/10940341 >.

JAACKS, L. M. et al. Type 2 diabetes: A 21st century epidemic. Best Pract Res Clin Endocrinol Metab, v. 30, n. 3, p. 331-343, Jun 2016. ISSN 1878-1594. Disponível em: < https://www.ncbi.nlm.nih.gov/pubmed/27432069 >.

JAMES, P. T. Obesity: the worldwide epidemic. Clin Dermatol, v. 22, n. 4, p. 276-280, 2004 Jul-Aug 2004. ISSN 0738-081X. Disponível em: < http://www.ncbi.nlm.nih.gov/pubmed/15475226 >.

JAMES, P. T. et al. The worldwide obesity epidemic. Obes Res, v. 9 Suppl 4, p. 228S233S, Nov 2001. ISSN 1071-7323. Disponível em: < http://www.ncbi.nlm.nih.gov/pubmed/11707546 >.

JIANG, L. et al. Activation of PPAR $\delta$ promotes mitochondrial energy metabolism and decreases basal insulin secretion in palmitate-treated $\beta$-cells. Mol Cell Biochem, v. 343, n. 1-2, p. 249-256, Oct 2010. ISSN 1573-4919. Disponível em: < http://www.ncbi.nlm.nih.gov/pubmed/20571903 >.

JONES, R. D.; HANCOCK, J. T.; MORICE, A. H. NADPH oxidase: a universal oxygen sensor? Free Radic Biol Med, v. 29, n. 5, p. 416-424, Sep 2000. ISSN 08915849. Disponível em: < http://www.ncbi.nlm.nih.gov/pubmed/11020663 >.

JUMP, D. B. The biochemistry of n-3 polyunsaturated fatty acids. J Biol Chem, v. 277, n. 11, p. 8755-8758, Mar 2002. ISSN 0021-9258. Disponível em: < http://www.ncbi.nlm.nih.gov/pubmed/11748246 >. 
KATO, T. et al. Palmitate impairs and eicosapentaenoate restores insulin secretion through regulation of SREBP-1c in pancreatic islets. Diabetes, v. 57, n. 9, p. 23822392, Sep 2008. ISSN 1939-327X. Disponível em: < http://www.ncbi.nlm.nih.gov/pubmed/18458149 >.

KEANE, D. C. et al. Arachidonic acid actions on functional integrity and attenuation of the negative effects of palmitic acid in a clonal pancreatic $\beta$-cell line. Clin Sci (Lond), v. 120 , n. 5, p. 195-206, Mar 2011. ISSN 1470-8736. Disponível em: < http://www.ncbi.nlm.nih.gov/pubmed/20840078 >.

KELPE, C. L. et al. Palmitate inhibition of insulin gene expression is mediated at the transcriptional level via ceramide synthesis. J Biol Chem, v. 278, n. 32, p. 3001530021, Aug 2003. ISSN 0021-9258. Disponível em: < http://www.ncbi.nlm.nih.gov/pubmed/12771145 >.

KOEPPEN, B. M., STANTON, B. A. Fisiologia. 2009.

LACY, P. E.; KOSTIANOVSKY, M. Method for the isolation of intact islets of Langerhans from the rat pancreas. Diabetes, v. 16, n. 1, p. 35-39, Jan 1967. ISSN 00121797. Disponível em: < http://www.ncbi.nlm.nih.gov/pubmed/5333500 >.

LANG, F.; ULLRICH, S.; GULBINS, E. Ceramide formation as a target in beta-cell survival and function. Expert Opin Ther Targets, v. 15, n. 9, p. 1061-1071, Sep 2011. ISSN 1744-7631. Disponível em: < http://www.ncbi.nlm.nih.gov/pubmed/21635197 >.

LIANG, H. et al. Palmitic acid-induced apoptosis in pancreatic $\beta$-cells is increased by liver $\mathrm{X}$ receptor agonist and attenuated by eicosapentaenoate. In Vivo, v. 25, n. 5, p. 711-718, 2011 Sep-Oct 2011. ISSN 1791-7549. Disponível em: < http://www.ncbi.nlm.nih.gov/pubmed/21753123 >.

LIN, N. et al. Mitochondrial reactive oxygen species (ROS) inhibition ameliorates palmitate-induced INS-1 beta cell death. Endocrine, v. 42, n. 1, p. 107-117, Aug 2012. ISSN 1559-0100. Disponível em: < http://www.ncbi.nlm.nih.gov/pubmed/22350662 >.

LIVAK, K. J.; SCHMITTGEN, T. D. Analysis of relative gene expression data using real-time quantitative PCR and the 2(-Delta Delta C(T)) Method. Methods, v. 25, n. 4, p. 402-408, Dec 2001. ISSN 1046-2023 (Print) 1046-2023 (Linking). Disponível em: < http://www.ncbi.nlm.nih.gov/entrez/query.fcgi?cmd=Retrieve\&db=PubMed\&dopt=Cita $\underline{\text { tion\&list uids }=11846609}>$.

LUCENA, C. F. et al. Omega-3 supplementation improves pancreatic islet redox status: in vivo and in vitro studies. Pancreas, v. 44, n. 2, p. 287-295, Mar 2015. ISSN 15364828. Disponível em: < http://www.ncbi.nlm.nih.gov/pubmed/25426612 >. 
LUO, P.; WANG, M. H. Eicosanoids, $\beta$-cell function, and diabetes. Prostaglandins Other Lipid Mediat, v. 95, n. 1-4, p. 1-10, Aug 2011. ISSN 1098-8823. Disponível em: < http://www.ncbi.nlm.nih.gov/pubmed/21757024 >.

LUPI, R. et al. Lipotoxicity in human pancreatic islets and the protective effect of metformin. Diabetes, v. 51 Suppl 1, p. S134-S137, Feb 2002. ISSN 0012-1797. Disponível em: < http://www.ncbi.nlm.nih.gov/pubmed/11815472 >.

Prolonged exposure to free fatty acids has cytostatic and pro-apoptotic effects on human pancreatic islets: evidence that beta-cell death is caspase mediated, partially dependent on ceramide pathway, and Bcl-2 regulated. Diabetes, v. 51, n. 5, p. 14371442, May 2002. ISSN 0012-1797. Disponível em: < http://www.ncbi.nlm.nih.gov/pubmed/11978640 >.

MAECHLER, P.; JORNOT, L.; WOLLHEIM, C. B. Hydrogen peroxide alters mitochondrial activation and insulin secretion in pancreatic beta cells. J Biol Chem, v. 274, n. 39, p. 27905-27913, Sep 1999. ISSN 0021-9258. Disponível em: < https://www.ncbi.nlm.nih.gov/pubmed/10488138 >.

MAEDLER, K. et al. Distinct effects of saturated and monounsaturated fatty acids on beta-cell turnover and function. Diabetes, v. 50, n. 1, p. 69-76, Jan 2001. ISSN 00121797. Disponível em: < http://www.ncbi.nlm.nih.gov/pubmed/11147797 >.

MANUKYAN, L. et al. Palmitate-induced impairments of $\beta$-cell function are linked with generation of specific ceramide species via acylation of sphingosine. Endocrinology, v. 156, n. 3, p. 802-812, Mar 2015. ISSN 1945-7170. Disponível em: < http://www.ncbi.nlm.nih.gov/pubmed/25535826 >.

MARIS, M. et al. Role of the saturated nonesterified fatty acid palmitate in beta cell dysfunction. J Proteome Res, v. 12, n. 1, p. 347-362, Jan 2013. ISSN 1535-3907. Disponível em: < http://www.ncbi.nlm.nih.gov/pubmed/23170928 >.

MARTINS, E. F. et al. Changes of fatty acid composition in incubated rat pancreatic islets. Diabetes Metab, v. 30, n. 1, p. 21-27, Feb 2004. ISSN 1262-3636. Disponível em: < http://www.ncbi.nlm.nih.gov/pubmed/15029094 >.

MELO, C. M.; TIRAPEGUI, J.; RIBEIRO, S. M. L. Gasto Energético Corporal: Conceitos, Formas de Avaliação e sua Relação com a Obesidade. Arq Bras Endrocrinol Metab, v. 52, n. 3, 2008.

MORGAN, D. et al. Glucose, palmitate and pro-inflammatory cytokines modulate production and activity of a phagocyte-like NADPH oxidase in rat pancreatic islets and 
a clonal beta cell line. Diabetologia, v. 50, n. 2, p. 359-369, Feb 2007. ISSN 0012186X. Disponível em: < http://www.ncbi.nlm.nih.gov/pubmed/17151863 >.

Association of $\mathrm{NAD}(\mathrm{P}) \mathrm{H}$ oxidase with glucose-induced insulin secretion by pancreatic beta-cells. Endocrinology, v. 150, n. 5, p. 2197-2201, May 2009. ISSN 1945-7170. Disponível em: < http://www.ncbi.nlm.nih.gov/pubmed/19147679 >.

MUECKLER, M. Facilitative glucose transporters. Eur J Biochem, v. 219, n. 3, p. 713 725, Feb 1994. ISSN 0014-2956. Disponível em: < http://www.ncbi.nlm.nih.gov/pubmed/8112322 >.

NELSON, D. L.; COX, M. M. Lehninger: Princípios de Bioquímica. São Paulo: Sarvier, 2002.

NETTLETON, J. A. Omega-3 fatty acids and health. 1995.

NEWSHOLME, P.; GAUDEL, C.; MCCLENAGHAN, N. H. Nutrient regulation of insulin secretion and beta-cell functional integrity. Adv Exp Med Biol, v. 654, p. 91114, 2010. ISSN 0065-2598. Disponível em: < http://www.ncbi.nlm.nih.gov/pubmed/20217496 >.

OGUZHAN, B. et al. Pancreatic islet function in omega3 fatty acid-depleted rats: Glucose metabolism and nutrient-stimulated insulin release. Endocrine, v. 29, n. 3, p. 457-466, Jun 2006. ISSN 1355-008X. Disponível em: < http://www.ncbi.nlm.nih.gov/pubmed/16943585 >.

OLIVEIRA, H. R. et al. Pancreatic beta-cells express phagocyte-like NAD $(\mathrm{P}) \mathrm{H}$ oxidase. Diabetes, v. 52, n. 6, p. 1457-1463, Jun 2003. ISSN 0012-1797. Disponível em: < http://www.ncbi.nlm.nih.gov/pubmed/12765957 >.

OLOFSSON, C. S. et al. Long-term exposure to glucose and lipids inhibits glucoseinduced insulin secretion downstream of granule fusion with plasma membrane. Diabetes, v. 56, n. 7, p. 1888-1897, Jul 2007. ISSN 1939-327X. Disponível em: < http://www.ncbi.nlm.nih.gov/pubmed/17456851 >.

OPRESCU, A. I. et al. Free fatty acid-induced reduction in glucose-stimulated insulin secretion: evidence for a role of oxidative stress in vitro and in vivo. Diabetes, v. 56, n. 12, p. 2927-2937, Dec 2007. ISSN 1939-327X. Disponível em: < http://www.ncbi.nlm.nih.gov/pubmed/17717282 >.

ORTSÄTER, H. Arachidonic acid fights palmitate: new insights into fatty acid toxicity in $\beta$-cells. Clin Sci (Lond), v. 120, n. 5, p. 179-181, Mar 2011. ISSN 1470-8736. Disponível em: < http://www.ncbi.nlm.nih.gov/pubmed/21044045 >. 
OYADOMARI, S.; ARAKI, E.; MORI, M. Endoplasmic reticulum stress-mediated apoptosis in pancreatic beta-cells. Apoptosis, v. 7, n. 4, p. 335-345, Aug 2002. ISSN 1360-8185. Disponível em: < https://www.ncbi.nlm.nih.gov/pubmed/12101393 >.

PALMA, A. et al. Conflitos de interesse na "guerra" contra a obesidade: é possível servir a dois senhores?: Saúde, Soc. São Paulo. 23: 1262-1274 p. 2014.

PI, J. et al. Reactive oxygen species as a signal in glucose-stimulated insulin secretion. Diabetes, v. 56, n. 7, p. 1783-1791, Jul 2007. ISSN 1939-327X. Disponível em: < http://www.ncbi.nlm.nih.gov/pubmed/17400930 >.

PINHEIRO, A. R. O.; FREITAS, S. F. T.; CORSO, A. C. T. Uma abordagem epidemiológica da obesidade: Rev. Nutr., Campinas. 17: 523-533 p. 2004.

PINNICK, K. et al. Reversibility of metabolic and morphological changes associated with chronic exposure of pancreatic islet beta-cells to fatty acids. J Cell Biochem, v. 109, n. 4, p. 683-692, Mar 2010. ISSN 1097-4644. Disponível em: < http://www.ncbi.nlm.nih.gov/pubmed/20069570 >.

PINTON, P. et al. Long-term modulation of mitochondrial $\mathrm{Ca} 2+$ signals by protein kinase C isozymes. J Cell Biol, v. 165, n. 2, p. 223-232, Apr 2004. ISSN 0021-9525. Disponível em: < http://www.ncbi.nlm.nih.gov/pubmed/15096525 >.

POITOUT, V. et al. Gluco-lipotoxicity of the pancreatic beta cell. Ann Endocrinol (Paris), v. 65, n. 1, p. 37-41, Feb 2004. ISSN 0003-4266. Disponível em: < http://www.ncbi.nlm.nih.gov/pubmed/15122090 >.

POPKIN, B. M.; GORDON-LARSEN, P. The nutrition transition: worldwide obesity dynamics and their determinants. Int J Obes Relat Metab Disord, v. 28 Suppl 3, p. S29, Nov 2004. Disponível em: < http://www.ncbi.nlm.nih.gov/pubmed/15543214 >.

RANDLE, P. J. et al. The glucose fatty-acid cycle. Its role in insulin sensitivity and the metabolic disturbances of diabetes mellitus. Lancet, v. 1, n. 7285, p. 785-789, Apr 1963. ISSN 0140-6736. Disponível em: < https://www.ncbi.nlm.nih.gov/pubmed/13990765 >.

RANG, H. P. Farmacologia. 2004.

REBELATO, E. et al. Low doses of hydrogen peroxide impair glucose-stimulated insulin secretion via inhibition of glucose metabolism and intracellular calcium oscillations. Metabolism, v. 59, n. 3, p. 409-413, Mar 2010. ISSN 1532-8600. Disponível em: < https://www.ncbi.nlm.nih.gov/pubmed/19800636 >. 
Control of the intracellular redox state by glucose participates in the insulin secretion mechanism. PLoS One, v. 6, n. 8, p. e24507, 2011. ISSN 1932-6203. Disponível em: < http://www.ncbi.nlm.nih.gov/pubmed/21909396 >.

RICHARD, D. et al. Polyunsaturated fatty acids as antioxidants. Pharmacol Res, v. 57, n. 6, p. 451-455, Jun 2008. ISSN 1043-6618. Disponível em: < http://www.ncbi.nlm.nih.gov/pubmed/18583147 >.

RISÉRUS, U. Fatty acids and insulin sensitivity. Curr Opin Clin Nutr Metab Care, v. 11, n. 2, p. 100-105, Mar 2008. ISSN 1363-1950. Disponível em: < http://www.ncbi.nlm.nih.gov/pubmed/18301083 >.

ROSE, D. P. Effects of dietary fatty acids on breast and prostate cancers: evidence from in vitro experiments and animal studies. Am J Clin Nutr, v. 66, n. 6 Suppl, p. 1513S1522S, Dec 1997. ISSN 0002-9165. Disponível em: < http://www.ncbi.nlm.nih.gov/pubmed/9394709 >.

SANTOS, L. R. et al. Oleic acid modulates metabolic substrate channeling during glucose-stimulated insulin secretion via NAD $(\mathrm{P}) \mathrm{H}$ oxidase. Endocrinology, v. 152, n. 10, p. 3614-3621, Oct 2011. ISSN 1945-7170. Disponível em: < http://www.ncbi.nlm.nih.gov/pubmed/21828179 >.

SARGSYAN, E.; BERGSTEN, P. Lipotoxicity is glucose-dependent in INS-1E cells but not in human islets and MIN6 cells. Lipids Health Dis, v. 10, p. 115, 2011. ISSN 1476-511X. Disponível em: < http://www.ncbi.nlm.nih.gov/pubmed/21745359 >.

SCHÖNFELD, P.; WOJTCZAK, L. Fatty acids as modulators of the cellular production of reactive oxygen species. Free Radic Biol Med, v. 45, n. 3, p. 231-241, Aug 2008. ISSN 0891-5849. Disponível em: < http://www.ncbi.nlm.nih.gov/pubmed/18482593 >.

SENER, A. et al. Altered $\mathrm{K}+$ fluxes and insulin release in pancreatic islets from omega3 fatty acid-depleted rats. Endocrine, v. 30, n. 2, p. 207-211, Oct 2006. ISSN 1355-008X. Disponível em: < http://www.ncbi.nlm.nih.gov/pubmed/17322581 >.

SHAO, S. et al. SREBP-1c, Pdx-1, and GLP-1R involved in palmitate-EPA regulated glucose-stimulated insulin secretion in INS-1 cells. J Cell Biochem, v. 111, n. 3, p. 634-642, Oct 2010. ISSN 1097-4644. Disponível em: < http://www.ncbi.nlm.nih.gov/pubmed/20589757 >.

SHARIFUL ISLAM, S. M. et al. Social and economic impact of diabetics in Bangladesh: protocol for a case-control study. BMC Public Health, v. 13, p. 1217, 2013. ISSN 1471-2458. Disponível em: http://www.ncbi.nlm.nih.gov/pubmed/24359558 >. 
SIMOPOULOS, A. P. Omega-3 fatty acids in inflammation and autoimmune diseases. $\mathbf{J}$ Am Coll Nutr, v. 21, n. 6, p. 495-505, Dec 2002. ISSN 0731-5724. Disponível em: < http://www.ncbi.nlm.nih.gov/pubmed/12480795 >.

SIRIWARDHANA, N.; KALUPAHANA, N. S.; MOUSTAID-MOUSSA, N. Health benefits of n-3 polyunsaturated fatty acids: eicosapentaenoic acid and docosahexaenoic acid. Adv Food Nutr Res, v. 65, p. 211-222, 2012. ISSN 1043-4526. Disponível em: < http://www.ncbi.nlm.nih.gov/pubmed/22361189 >.

SKERRETT, P. J.; HENNEKENS, C. H. Consumption of fish and fish oils and decreased risk of stroke. Prev Cardiol, v. 6, n. 1, p. 38-41, 2003. ISSN 1520-037X. Disponível em: < http://www.ncbi.nlm.nih.gov/pubmed/12624561 >.

STEIN, D. T. et al. The insulinotropic potency of fatty acids is influenced profoundly by their chain length and degree of saturation. J Clin Invest, v. 100, n. 2, p. 398-403, Jul 1997. ISSN 0021-9738. Disponível em: < http://www.ncbi.nlm.nih.gov/pubmed/9218517 >.

SUMMERS, S. A. Ceramides in insulin resistance and lipotoxicity. Prog Lipid Res, v. 45, n. 1, p. 42-72, Jan 2006. ISSN 0163-7827. Disponível em: < http://www.ncbi.nlm.nih.gov/pubmed/16445986 >.

SYED, I. et al. Increased phagocyte-like NADPH oxidase and ROS generation in type 2 diabetic ZDF rat and human islets: role of Rac1-JNK1/2 signaling pathway in mitochondrial dysregulation in the diabetic islet. Diabetes, v. 60, n. 11, p. 2843-2852, Nov 2011. ISSN 1939-327X. Disponível em: < http://www.ncbi.nlm.nih.gov/pubmed/21911753 >.

TAKAHASHI, A. et al. Transgenic mice overexpressing nuclear SREBP-1c in pancreatic beta-cells. Diabetes, v. 54, n. 2, p. 492-9, Feb 2005. ISSN 0012-1797. Disponível em: < http://www.ncbi.nlm.nih.gov/pubmed/15677507 >.

THOMAS, H. E.; KAY, T. W. Intracellular pathways of pancreatic $\beta$-cell apoptosis in type 1 diabetes. Diabetes Metab Res Rev, v. 27, n. 8, p. 790-6, Nov 2011. ISSN 15207560. Disponível em: < http://www.ncbi.nlm.nih.gov/pubmed/22069261 >.

WANG, H. H. et al. Fish oil increases antioxidant enzyme activities in macrophages and reduces atherosclerotic lesions in apoE-knockout mice. Cardiovasc Res, v. 61, n. 1, p. 169-176, Jan 2004. ISSN 0008-6363. Disponível em: < http://www.ncbi.nlm.nih.gov/pubmed/14732214 >. 
WANG, X.; CHAN, C. B. n-3 polyunsaturated fatty acids and insulin secretion. J Endocrinol, v. 224, n. 3, p. R97-106, Mar 2015. ISSN 1479-6805. Disponível em: < http://www.ncbi.nlm.nih.gov/pubmed/25486966 >.

WEIDINGER, A.; KOZLOV, A. V. Biological Activities of Reactive Oxygen and Nitrogen Species: Oxidative Stress versus Signal Transduction. Biomolecules, v. 5, n. 2, p. 472-484, 2015 2015. ISSN 2218-273X. Disponível em: < http://www.ncbi.nlm.nih.gov/pubmed/25884116 >.

WHO, W. H. O.-. Global Health Observatory Data: overweight and obesity 2014.

YAHAGI, N. et al. A crucial role of sterol regulatory element-binding protein-1 in the regulation of lipogenic gene expression by polyunsaturated fatty acids. J Biol Chem, v. 274, n. 50, p. 35840-35844, Dec 1999. ISSN 0021-9258. Disponível em: < http://www.ncbi.nlm.nih.gov/pubmed/10585468 >.

YAQOOB, P.; CALDER, P. C. N-3 polyunsaturated fatty acids and inflammation in the arterial wall. Eur J Med Res, v. 8, n. 8, p. 337-354, Aug 2003. ISSN 0949-2321. Disponível em: < http://www.ncbi.nlm.nih.gov/pubmed/12915325 >.

YUAN, $\mathrm{H}$. et al. NADPH oxidase 2-derived reactive oxygen species mediate FFAsinduced dysfunction and apoptosis of $\beta$-cells via JNK, p38 MAPK and p53 pathways. PLoS One, v. 5, n. 12, p. e15726, 2010. ISSN 1932-6203. Disponível em: < http://www.ncbi.nlm.nih.gov/pubmed/21209957 >.

ZHOU, Y. P.; GRILL, V. Long term exposure to fatty acids and ketones inhibits B-cell functions in human pancreatic islets of Langerhans. J Clin Endocrinol Metab, v. 80, n. 5, p. 1584-1590, May 1995. ISSN 0021-972X. Disponível em: < https://www.ncbi.nlm.nih.gov/pubmed/7745004 >.

ZHOU, Y. P.; LING, Z. C.; GRILL, V. E. Inhibitory effects of fatty acids on glucoseregulated B-cell function: association with increased islet triglyceride stores and altered effect of fatty acid oxidation on glucose metabolism. Metabolism, v. 45, n. 8, p. 981986, Aug 1996. ISSN 0026-0495. Disponível em: < https://www.ncbi.nlm.nih.gov/pubmed/8769356 >. 